\title{
USO DE ARDÓSIA NA CONSTRUÇÃO DE CELAS DE MATERNIDADE: I - EFEITO SOBRE O AMBIENTE E COMPORTAMENTO DE SUÍNOS
}

\section{JAQUELINE DE O. CASTRO ${ }^{1}$, ALESSANDRO T. CAMPOS ${ }^{2}$, RONY A. FERREIRA ${ }^{3}$, TADAYUKI YANAGI JÚNIOR ${ }^{4}$, HUGO C. TADEU ${ }^{5}$}

\begin{abstract}
RESUMO: O presente trabalho teve o objetivo de avaliar o uso da ardósia na construção de celas de maternidade, sendo monitoradas 12 matrizes e 139 leitões em celas confeccionadas de alvenaria e ardósia (tratamentos). Imagens digitais foram avaliadas por meio de dois etogramas. As variáveis ambientais foram registradas às $9 \mathrm{~h}$ e $15 \mathrm{~h}$. O desempenho dos leitões foi determinado pelo peso ao nascimento e à desmama, ganho de peso diário e final. Na cela de alvenaria, os leitões passaram menos tempo mamando $(25,62 \%)$ e mais no escamoteador $(38,91 \%)$ que aqueles mantidos na cela de ardósia (29,22\% mamando e 24,90\% no escamoteador). As variáveis ambientais e os índices de conforto mostraram que o microclima na cela de ardósia apresentou-se mais confortável aos leitões, enquanto aquele em alvenaria foi mais confortável às matrizes. Os leitões mantidos nas celas de alvenaria apresentaram ganho de peso diário semelhante aos alojados em celas de ardósia $(\mathrm{P}<0,05)$. Os comportamentos das matrizes foram semelhantes em ambos os tipos de cela, apresentando maior frequência do comportamento "deitado". A ardósia pode ser uma alternativa vantajosa à alvenaria na construção de celas no setor de maternidade para suínos, por apresentar maior impermeabilidade, facilidade de limpeza e desinfecção.
\end{abstract}

PALAVRAS-CHAVE: ardósia, comportamento animal, instalações para suínos, material de construção, suinocultura.

\section{THE USE OF SLATE IN THE BUILDING OF SWINE FARROWING STALLS: I -EFFECT ON THE ENVIRONMENT AND THE SWINE BEHAVIOUR}

\begin{abstract}
It was aimed with the present study to evaluate the use of slate in the construction of farrowing stalls. Twelve sows and one hundred thirty nine piglets were monitored in cell built with masonry and slate (treatments). Digital images were evaluated through two ethogram. The environmental variants were evaluated at 9 am and $3 \mathrm{pm}$. The piglets' performance was determinated by birth and weaning weights, and daily and final weight gains. At the masonry cell the piglets spent less time nursing $(25.62 \%)$ and more in the creep $(38.91 \%)$ than those kept in the slate cell $(29.22 \%$ nursing and $24.90 \%$ in the creep). And the environmental variants and comfort index showed that the microclimate into the slate cell was more comfortable to piglets, while that around the masonry was more comfortable to sows. The piglets kept in the masonry cell presented daily weight gain similar to the ones housed in the slate cell $(\mathrm{P}<0.05)$. The sows' behaviors were similar in both types of cell, showing higher frequency of the "laying" behavior. Slate can be an advantageous alternative to masonry construction of cell in the field of farrowing housing for swine, due to its higher impermeability, easy for cleaning and disinfection.
\end{abstract}

KEYWORDS: slate, animal behavior, swine housing, building material, piggery.

\footnotetext{
${ }^{1}$ Doutoranda em Engenharia Agrícola, UFLA, Câmpus Universitário, Caixa Postal 3037, Lavras - MG, Bolsista da CAPES, jaqueline.oliveiracastro@yahoo.com.br.

${ }^{2}$ Prof. Adjunto, Departamento de Engenharia, UFLA, Lavras - MG.

${ }^{3}$ Prof. Adjunto, Departamento de Zootecnia, UFVJM, Diamantina - MG.

${ }^{4}$ Prof. Associado, Departamento de Engenharia, UFLA, Lavras - MG .

${ }^{5}$ Graduando em Agronomia, UFLA, Lavras - MG.

Recebido pelo Conselho Editorial em: 20-5-2010
}

Aprovado pelo Conselho Editorial em: 13-4-2011 


\section{INTRODUÇÃO}

A partir da década de 1970, a produção de suínos no Brasil começou a ser realizada em sistemas de confinamento, com o objetivo de melhorar o controle sanitário, reduzir a perda energética dos animais e aumentar a produtividade. A partir daí, estudos começaram a ser realizados no intuito de se conhecer a interação animal x ambiente $\mathrm{x}$ instalação e otimizar o sistema produtivo (SAMPAIO et al., 2007).

Em condições tropicais, o desconforto térmico é frequente, constituindo-se em um dos principais problemas da moderna suinocultura (SILVA et al., 2007). Um dos maiores desafios relacionados ao conforto térmico e bem-estar animal encontra-se na maternidade, na qual se têm dois ambientes distintos a serem avaliados, com exigências bem diferenciadas (PANDORFI et al., 2004).

A organização do mercado internacional de carne trouxe à cena a questão do bem-estar animal (NÄ̈̈̈S et al., 2008). Frente às atuais demandas, não se pode mais considerar sistema de produção animal ou cadeia produtiva, sem considerar o conceito de bem-estar na produção.

As formas de avaliação do conforto animal que vêm ganhando destaque nos últimos anos são aquelas que utilizam métodos não invasivos. De acordo com BORGES (2008), algumas técnicas, como a análise de imagens, o estudo de vocalização e nível de pressão sonora, avaliam a resposta do animal em situações adversas e podem ser registradas sem estresse, perturbação ou manipulação do animal. Nesse caso, os próprios animais são usados como biossensores às variações do ambiente.

A produção intensiva de suínos somente é possível com os avanços tecnológicos em nutrição, genética, manejo e controle ambiental, que possibilitaram ao animal expressar todo o seu potencial genético (CORDEIRO et al., 2007). Neste âmbito, as edificações constituem um dos fatores mais importantes no planejamento dos sistemas de produção, em que, após a execução da obra, torna-se difícil e onerosa qualquer alteração estrutural (OLIVEIRA \& SILVA, 2006).

Para que um novo material de construção seja implantado, estudos relacionados ao ambiente e ao bem-estar animal devem ser conduzidos para que não ocorram perdas produtivas relacionadas a esses materiais. A ardósia é uma rocha que sofreu metamorfismo regional sobre rochas sedimentares clásticas finas. Apresenta granulação fina, foliação tabular perfeita, sem faixas (BRANCO, 2010; COSTA et al., 2001).

Dentre as propriedades físicas da ardósia, incluem-se clivagem preferencial; dureza média; baixa porosidade (CHIODI FILHO et al., 2003), e segundo ALBUQUERQUE (2003) não existe uma porosidade definida e sim uma irregularidade muito grande, com sobreposição de pequenas camadas sedimentadas; alta resistência mecânica, minerais constituintes resistentes ao intemperismo. Devido a estas características, esta rocha apresenta atributos como durabilidade e facilidade de manutenção e limpeza. Esses atributos asseguram grande confiabilidade do seu uso em várias aplicações na construção civil (CHIODI FILHO et al., 2003), apresentando, ainda, a vantagem de poder ser aparafusada, possibilitando ser montada e desmontada.

Dada a abundância em que a ardósia é encontrada e comercializada no Estado de Minas Gerais, onde se encontra o principal jazimento mundial de ardósias de alta qualidade atualmente conhecido e explorado (AMAR, 2010), e devido às suas características físicas, esta rocha mostra-se extremamente interessante para ser empregada na construção de celas no setor de maternidade na suinocultura. Ademais, sua maior impermeabilidade e maior potencial de proporcionar melhores condições de higienização e desinfecção, se comparada à alvenaria, torna-se interessante o desenvolvimento de estudos sobre o emprego deste material, inclusive no que se refere aos aspectos relacionados ao conforto apresentado aos animais.

Com o presente trabalho, objetivou-se avaliar o ambiente térmico e o comportamento de matrizes e leitões em celas no setor de maternidade, confeccionadas com ardósia e alvenaria, com vistas a propor um material alternativo para construção destes compartimentos nas instalações. 


\section{MATERIAL E MÉTODOS}

O trabalho foi realizado em uma granja comercial de suínos em ciclo completo, localizada na Mesorregião Metropolitana de Belo Horizonte - MG, latitude 19²6'56" S, longitude 4444'52' W, altitude de $718 \mathrm{~m}$ e clima tropical chuvoso (Aw), segundo classificação de Köeppen. O experiemnto foi realizado no período de 20 de abril a 10 maio de 2009, de modo a contemplar o ciclo completo dos leitões na maternidade (do nascimento ao desmame).

$\mathrm{O}$ experimento foi conduzido em salas de maternidade com telhado em duas águas, coberto com telhas do tipo francesa, pé-direito de $3,6 \mathrm{~m}$, largura de $8 \mathrm{~m}$ e comprimento de $21 \mathrm{~m}$, dotado de cortinas laterais de polietileno amarelo, possuindo 24 celas de maternidade por sala, sendo a dimensão das celas de $3 \mathrm{~m}$ de comprimento por 1,70 $\mathrm{m}$ de largura. $\mathrm{O}$ escamoteador possui $0,5 \mathrm{~m}$ de comprimento por 1,70 m de largura (Figura 1), com uma lâmpada incandescente de $150 \mathrm{~W}$, para aquecimento dos leitões, instalada na parte superior, abaixo da tampa móvel.
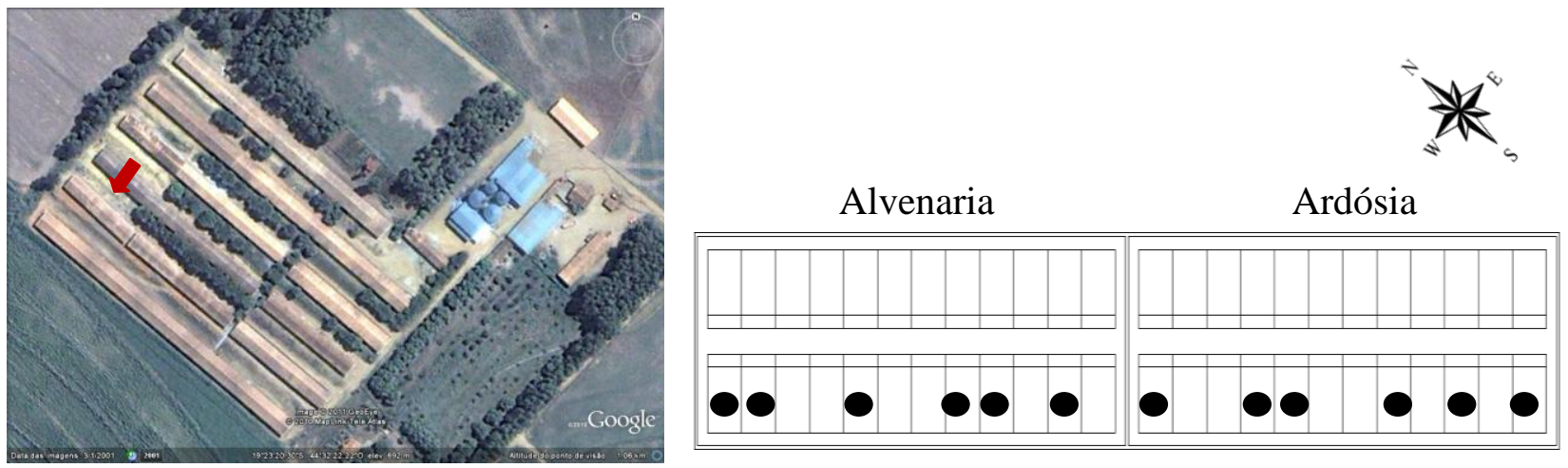

FIGURA 1. Localização da maternidade dentro da granja (esquerda) e representação esquemática da distribuição dos tratamentos, celas confeccionas em alvenaria e ardósia (direita). Farrowing housing location within the farm (left) and schematic representation of the distribution of treatments, cell built with masonry and slate.

Com a finalidade de evitar o efeito da orientação da instalação no ambiente, o lado da sala em que não incidia sol foi escolhido para dispor os tratamentos.

Os dados foram obtidos em duas diferentes salas, onde foram alojados 139 leitões e 12 matrizes de linhagem comercial, sendo a unidade experimental composta por uma celamaternidade (seis celas em cada tratamento) que alojava as matrizes e suas respectivas leitegadas. Os tratamentos foram os tipos de materiais utilizados para a confecção das celas-maternidade, alvenaria de tijolos furados e placas de ardósia com espessuras de $0,17 \mathrm{~m} \mathrm{e} 0,05 \mathrm{~m}$, respectivamente (Figura 2).

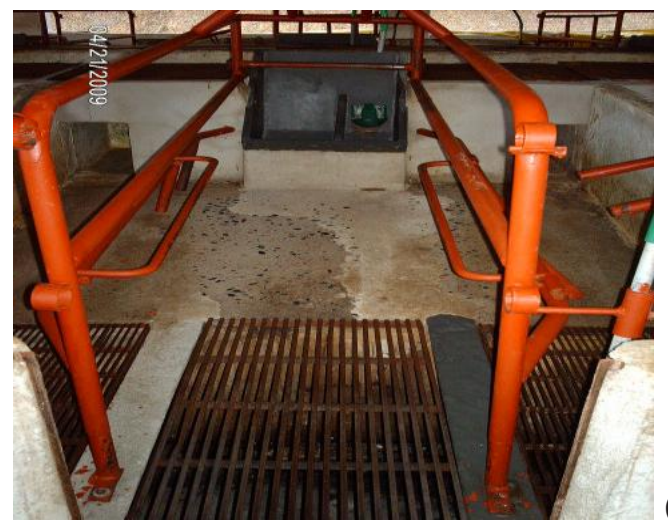

(a)

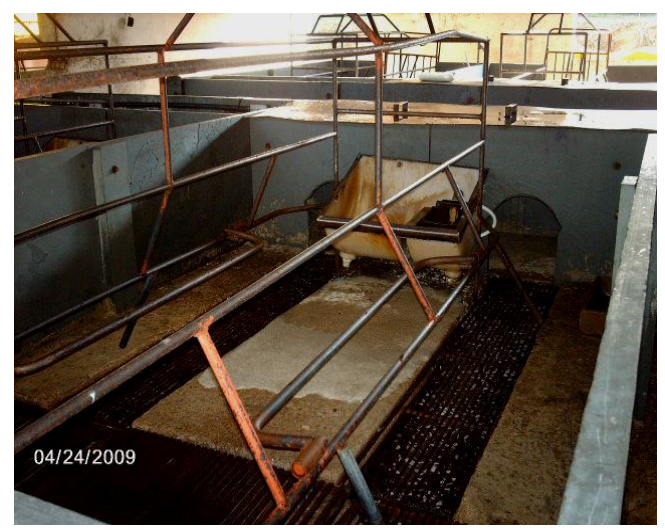

(b)

FIGURA 2. Celas maternidade confeccionadas em alvenaria (a) e placas de ardósia (b). Farrowing stalls built with masonry (a) and masonry slate boards (b). 
O registro de dados comportamentais ocorreu a cada três dias, a partir do nascimento dos leitões, durante todo o período experimental, por meio de imagens digitais tomadas a cada 15 minutos, no período de 7h30 às 16h, com câmera digital Benq modelo DC C500.

$\mathrm{O}$ manejo de rotina na maternidade consistia na alimentação das matrizes às $7 \mathrm{~h} 30,13 \mathrm{~h} 30$ e às 17h. Nos dois primeiros dias de vida dos leitões, eram feitos os cuidados de corte dos dentes e da cauda, e ministradas medicações preventivas (aplicação de glicose e ferro), posteriormente eram feitas outras medicações preventivas.

Utilizou-se o registro das imagens para confecção de dois etogramas, um para matrizes e outro para leitões. Os comportamentos foram quantificados por meio de etograma adaptado de SOUZA (2007), em que se observou a frequência comportamental de todos os leitões de cada cela: se estavam bebendo, mamando, comendo ração, deitados fora do escamoteador, explorando o ambiente e se havia interação entre leitões ou interação agonística entre os leitões. A avaliação comportamental das matrizes foi realizada segundo etograma adaptado de PANDORFI et al. (2006), que permitiu quantificar a frequência com que as matrizes estavam cheirando, comendo, bebendo, deitadas, sentadas, ajoelhadas e em pé.

No interior das instalações, o ambiente térmico foi monitorado em seis celas-maternidade em cada tratamento, que alojavam as matrizes e suas respectivas leitegadas. Foram feitas mensurações diárias do ambiente térmico no interior das celas de maternidade, a $40 \mathrm{~cm}$ do piso, nos horários das 9 e $15 \mathrm{~h}$, para estudo da eficiência térmica em cada tratamento, sendo registradas as temperaturas de bulbo seco $\left(\mathrm{Tbs},{ }^{\circ} \mathrm{C}\right)$ e globo negro $\left(\mathrm{Tg},{ }^{\circ} \mathrm{C}\right)$, a umidade relativa do ar (UR, \%) e a velocidade do ar $\left(\mathrm{Va}, \mathrm{m} \mathrm{s}^{-1}\right)$. Para tanto, foram utilizados os equipamentos: termo-higrômetro digital (modelo Alla France, escala interna: $-50+70{ }^{\circ} \mathrm{C} /$ externo: $-10+70{ }^{\circ} \mathrm{C} \pm, 1{ }^{\circ} \mathrm{C}$ e $8 \%$ ), globo negro e anemômetro (Instrutherm), para a determinação da eficiência térmica nas celas de alvenaria e ardósia. Com os dados ambientais obtidos, foram calculados o Índice de Temperatura do Globo e Umidade (ITGU), e Carga Térmica Radiante (CTR).

O Índice de Temperatura do Globo e Umidade (ITGU), descrito por BUFFINGTON et al. (1981), empregado por diversos pesquisadores, foi calculado e avaliado por meio da eq.(1):

$$
\mathrm{ITGU}=\mathrm{Tg}+0,36 \mathrm{Tpo}-330,08
$$

em que,

$\mathrm{Tg}$ - temperatura de globo negro, $\mathrm{K}$, e

Tpo - temperatura de ponto de orvalho, $\mathrm{K}$.

Como instrumento para a avaliação dos níveis de conforto térmico, a Carga Térmica Radiante, descrita por ESMAY (1982), foi calculada por meio da eq.(2):

$$
\mathrm{CTR}=\sigma(\mathrm{TRM})^{4}\left(\mathrm{~W} \mathrm{~m}^{-2}\right)
$$

sendo:

$$
\mathrm{TRM}=100\left\{\left[2,51(\mathrm{VV})^{0,5}(\mathrm{Tg}-\mathrm{Tbs})+(\mathrm{Tg} / 100)^{4}\right]^{0,25}\right\}
$$

em que,

TRM - temperatura radiante média, $\mathrm{K}$;

VV - velocidade do vento, $\mathrm{m} \mathrm{s}^{-1}$;

$\mathrm{Tg}$ - temperatura de globo negro, $\mathrm{K}$;

Tbs - temperatura de bulbo seco, k, e $\sigma-5,67 \times 10^{-8}$ (Constante de Stefan-Boltzmann), $\mathrm{K}^{-4} \mathrm{~W} \mathrm{~m}^{-2}$.

A temperatura da superfície (TS) dos materiais utilizados na confecção das celas na maternidade também foi mensurada por meio de termômetro sem contato (IMPAC IP-550, $\pm 2{ }^{\circ} \mathrm{C}$ ), durante todos os dias da avaliação comportamental, nos horários das $9 \mathrm{~h}$ e $15 \mathrm{~h}$. 
As massas corporais dos leitões foram avaliadas no dia do nascimento e no dia do desmame para avaliação de desempenho, por meio de uma balança digital (ITE JT-875, $\pm 10 \mathrm{~g}$ ), sendo avaliados o peso ao nascimento (PN) e ao desmame (PD), o ganho de peso total (GPT) e o ganho de peso diário (GPD) dos leitões .

O manejo rotineiro da granja foi mantido (alimentação, limpeza, castração, vacinação, dentre outros procedimentos)

Os dados referentes às variáveis comportamentais foram analisados de forma não paramétrica. As análises estatísticas referentes a Tbs, UR, ITGU, CTR e TS foram realizadas utilizando um delineamento em blocos casualizados, em um esquema de parcelas subdivididas, sendo as parcelas os tratamentos (alvenaria e ardósia), e as subparcelas, os horários. Para a formação dos blocos, foi utilizada a posição das celas no interior das salas. Para avaliar o desempenho dos animais, utilizou-se um delinemamento em blocos casualizados, obedescendo ao seguinte modelo matemático:

$$
Y i j k=\mu+B j+M i+\varepsilon i j+H k+\theta j k+M H i k+\delta i j k ;
$$

em que,

Yijk - efeito do material de construção i (i=1 e 2) no horário j (j=9 e15) na repetição k $(\mathrm{k}=1,2 \ldots 6)$

$\mu$ - média geral;

$\mathrm{Bj}$ - efeito do posicionamento da cela $\mathrm{j}$;

Mi - efeito do material de construção i;

cij - erro aleatório a;

Hk - efeito do horário k;

$\theta \mathrm{jk}$ - erro aleatório b;

MHik - efeito da interação do material de construção i com o horário de coleta de dados k, e

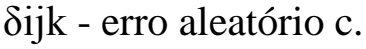

\section{RESULTADOS E DISCUSSÃO}

A temperatura de bulbo seco (Tbs) e a temperatura da superfície (TS) dos materiais não sofreram variação $(\mathrm{P}>0,05)$ pelos materiais de construção utilizados; entretanto, a umidade relativa (UR), o índice de temperatura do globo e umidade (ITGU) e a carga térmica radiante (CTR) foram superiores $(\mathrm{P}<0,05)$ nas celas construídas com ardósia (Tabela 1).

TABELA 1. Valores médios diários de temperatura de bulbo seco (Tbs); umidade relativa do ar (UR); índice de temperatura de globo e umidade (ITGU); carga térmica radiante (CTR); temperatura da superfície dos materiais (TS), às $9 \mathrm{~h}$ e $15 \mathrm{~h}$ em celas de maternidade para suínos, construídas de alvenaria de tijolos furados ou ardósia. Daily average values of dry bulb temperature (Tbs), relative humidity of the air (UR), black globe temperature and humidity index (ITGU), thermal heat load (CTR), surface temperature of the materials (TS) at $9 \mathrm{am}$ and $15 \mathrm{pm}$, in the swine nursery stalls, built of slate and masonry.

\begin{tabular}{ccrrrrr}
\hline \multirow{2}{*}{ Variáveis } & \multicolumn{2}{c}{$9 \mathrm{~h}$} & & \multicolumn{2}{c}{$15 \mathrm{~h}$} & \multirow{2}{*}{ C.V.(\%) } \\
\cline { 2 - 3 } \cline { 5 - 6 } \cline { 5 - 6 } & Alvenaria & Ardósia & & Alvenaria & Ardósia & \\
\hline Tbs & $20,83 \mathrm{a}$ & $22,00 \mathrm{a}$ & & $25,83 \mathrm{a}$ & $27,17 \mathrm{a}$ & 4,46 \\
UR & $86,83 \mathrm{a}$ & $85,00 \mathrm{a}$ & & $64,50 \mathrm{a}$ & $60,50 \mathrm{~b}$ & 3,65 \\
ITGU & $68,33 \mathrm{a}$ & $70,17 \mathrm{~b}$ & & $73,83 \mathrm{a}$ & $75,17 \mathrm{~b}$ & 1,75 \\
CTR & $428,33 \mathrm{a}$ & $434,33 \mathrm{~b}$ & & $468,67 \mathrm{a}$ & $471,67 \mathrm{a}$ & 0,81 \\
TS & $23,00 \mathrm{a}$ & $23,50 \mathrm{a}$ & & $27,50 \mathrm{a}$ & $27,83 \mathrm{a}$ & 1,93 \\
\hline
\end{tabular}

Médias seguidas de mesma letra na linha são estatisticamente iguais, pelo teste $\mathrm{F}(\mathrm{P}<0,05)$. 
Os valores médios de Tbs mantiveram-se abaixo das condições de conforto para leitões na maternidade, de 32 a $28{ }^{\circ} \mathrm{C}$, recomendado por SILVA (1999), tanto para a alvenaria, quanto para a ardósia.

FERREIRA et al. (2007), em experimento avaliando comportamento e parâmetros fisiológicos de leitões, nas primeiras 24 horas de vida, observaram que a temperatura retal desses animais aumentou após nove horas do nascimento; entretanto, os leitões ainda possuíam pequena capacidade de regular sua temperatura corporal, principalmente por causa do seu incompleto desenvolvimento hipotalâmico, sendo imprescindível o uso de fontes suplementares de calor nessa fase.

Nos horários avaliados, as temperaturas de bulbo seco (Tbs) mantiveram-se acima dos valores ideais para o conforto de matrizes que, segundo BAÊTA \& SOUZA (1997) e TEIXEIRA (1997), deve estar entre 12 e $18{ }^{\circ} \mathrm{C}$.

MARTINS et al. (2008a), ao avaliarem as respostas termorreguladoras de matrizes suínas híbridas em lactação, observaram aumento na temperatura retal e frequência respiratória nos períodos de pico de calor diários (12 horas às 16 horas), o que, segundo eles, demonstrou baixa adaptabilidade ao estresse calórico. Esses mesmos autores afirmaram que essas fêmeas podem ser criadas em ambiente com temperatura acima do conforto térmico, desde que sejam adotadas medidas para minimizar o estresse calórico no turno da tarde, principalmente para primíparas.

A umidade relativa do ar (UR) não foi afetada $(\mathrm{P}>0,05)$ pelos materiais de construção para o horário de $9 \mathrm{~h}$, apresentando-se acima do recomendado para o conforto animal, 60 e $70 \%$ (NÄ̈̈S, 1989). Diferentemente do ocorrido pela manhã, às $15 \mathrm{~h}$, a UR foi influenciada $(\mathrm{P}<0,05)$ pelos tratamentos, sendo que, nas celas construídas de ardósia, a UR mostrou valores inferiores às construídas de alvenaria. Ambos os valores observados para esse horário demonstraram condição de conforto para os animais.

O fato de a UR apresentar valor inferior para a sala com celas de ardósia deve-se à proporcionalidade inversa entre Tbs e UR encontrada naquele ambiente.

As celas construídas de ardósia apresentaram maiores valores $(\mathrm{P}<0,05)$ de ITGU no horário de $9 \mathrm{~h}$. Os valores deste índice variaram de forma inversa aos valores da umidade relativa do ar, assim como constataram CAMPOS et al. (2004) em instalação para bovinos.

Para os leitões, tanto as celas de alvenaria quanto as de ardósia promoveram situação de desconforto ambiental especificamente na região externa ao escamoteador, pois esses animais requerem maiores valores de ITGU, entre 82 e 84 (PANDORFI et al., 2005), sendo indispensável a fonte de calor no interior do escamoteador, para evitar o estresse por frio, já que esses animais podem ter seu desempenho afetado pelo ambiente inadequado.

Às $9 \mathrm{~h}$, nas celas confeccionadas de ardósia, e às 15h, nas celas de alvenaria, as matrizes encontravam-se em conforto, pois os valores de ITGU situaram-se próximos ao valor tido como ideal, 72 (TURCO et al., 1998). Apesar de a CTR ter-se mostrado mais elevada no período da tarde, no horário das $9 \mathrm{~h}$ ela foi maior $(\mathrm{P}<0,05)$ nas celas construídas de ardósia. De forma similar ao ITGU, a CTR também se aproximou do valor de conforto para os animais, que deve estar próximo a $450 \mathrm{~W} \mathrm{~m}^{-2}$ (BAÊTA \& SOUZA, 1997).

As temperaturas das superfícies dos materiais (TS) variaram de forma semelhante, pois não foi observada diferença significativa entre os tratamentos $(\mathrm{P}>0,05)$. Dessa forma, os materiais ardósia e alvenaria mostraram-se semelhantes em suas condições térmicas. Contudo, a condutividade térmica da ardósia é relativamente alta $\left(2,10 \mathrm{~W} \mathrm{~m}^{-1}{ }^{\circ} \mathrm{C}^{-1}\right)$, quando comparada à do concreto comum $\left(1,74 \mathrm{~W} \mathrm{~m}^{-1}{ }^{\circ} \mathrm{C}^{-1}\right)$ e á do tijolo furado $\left(0,91 \mathrm{~W} \mathrm{~m}^{-1}{ }^{\circ} \mathrm{C}^{-1}\right)$, ou seja, ela possui maior capacidade de alterar o ambiente dentro das instalações (NÄ̈̈S, 1989).

Os resultados comportamentais para os eventos de maior ocorrência apontam que os leitões que se encontravam nas celas de alvenaria passaram menos tempo mamando ou deitados e 
utilizaram mais o escamoteador, em relação aos que estavam nas celas de ardósia (Figura 2). Como a frequência de acesso ao escamoteador está diretamente relacionada à variação de temperatura do ambiente, esse fato pode ser atribuído a menores temperaturas do microambiente encontrado nas celas de alvenaria (Tabela 1). Esses resultados corroboram aqueles obtidos por SILVA et al. (2005), que, ao estudarem diferentes fontes de aquecimento nos abrigos escamoteadores, verificaram que reduções da temperatura ambiente nas salas de maternidade levaram ao aumento na procura por fonte artificial de calor.

Nos dois tratamentos, os comportamentos das matrizes foram semelhantes, uma vez que apresentaram maior frequência dos comportamentos deitado, em pé e comendo. Entretanto, as matrizes alojadas nas celas confeccionadas em ardósia passaram 2,23\% menos tempo de pé, 1,80\% menos tempo comendo e 5,09\% mais tempo deitadas, mostrando que os animais alojados nas celas de maternidade, confeccionadas em ardósia, apresentaram maior predileção ao comportamento de se deitarem. O tempo que passaram deitadas pode ter conferido maior tempo de amamentação aos leitões (Figuras 2 e 3). Estes resultados contrapõem-se aos encontrados por MARTINS et al. (2008b), que observaram que matrizes suínas lactantes, mantidas em ambiente quente, são mais reativas nos períodos mais quentes do dia e reduzem a frequência da postura em decúbito lateral e o número de amamentações terminadas pelos leitões.

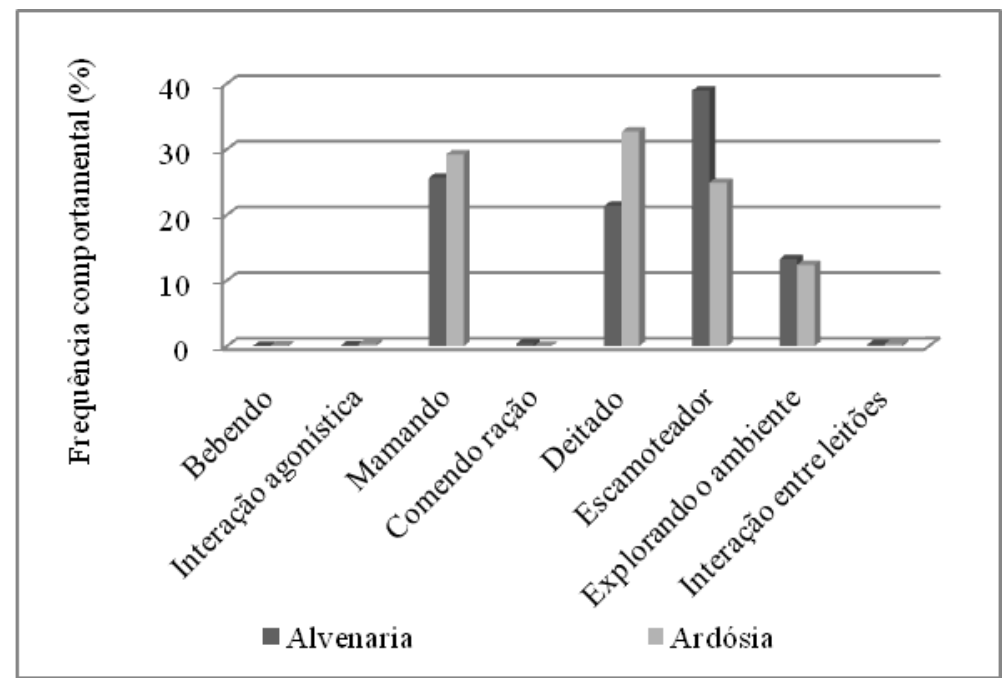

FIGURA 3. Comportamento (\%) de leitões em celas-maternidade confeccionadas em alvenaria ou ardósia. Behavior of piglets in nursery stalls built of masonry and slate.

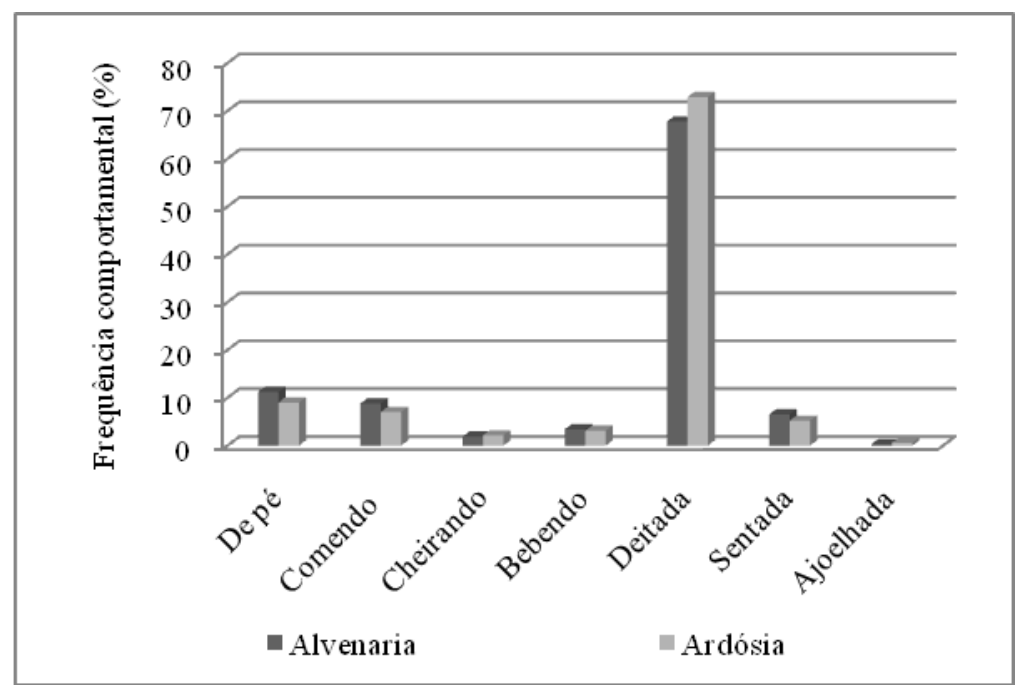

FIGURA 4. Comportamento (\%) de matrizes em celas-maternidade confeccionadas em alvenaria ou ardósia. Behavior of sows in nursery stalls built of masonry and slate. 
Segundo MARTINS \& COSTA (2008), em condições de estresse calórico, são observadas alterações fisiológicas e comportamentais da conduta materna, o que leva à queda na produção de leite, a qual influencia negativamente na produtividade da granja. Porém, neste experimento, o peso dos leitões ao desmame não foi afetado.

$\mathrm{O}$ peso ao nascimento $(\mathrm{PN})$ e o ganho de peso diário (GPD) não sofreram variação $(\mathrm{P}>0,05)$ em função dos materiais de construção (Tabela 2). Entretanto, o peso ao desmame (PD) e o ganho de peso $(\mathrm{GPT})$ foram superiores $(\mathrm{P}<0,05)$ nas celas de alvenaria (Tabela 2$)$.

TABELA 2. Valores médios do peso ao nascimento (PN kg), peso ao desmame (PD kg), ganho de peso (GPT kg) e ganho de peso diário (GPD kg dia ${ }^{-1}$ ) de leitões alojados em celas-maternidade construídas em alvenaria de tijolos furados ou ardósia. Birth weight (PN kg), weaning weight (PD kg), weight gain (GPT kg) and daily weight gain (GPD kg dia ${ }^{-1}$ ) of piglets housed in nursery stalls built in masonry and slate.

\begin{tabular}{ccccc}
\hline Tratamento & PN & PD & GPT & GPD \\
\hline Alvenaria & $1,47 \mathrm{a}$ & $6,08 \mathrm{a}$ & $4,51 \mathrm{a}$ & $0,217 \mathrm{a}$ \\
Ardósia & $1,50 \mathrm{a}$ & $5,61 \mathrm{~b}$ & $4,09 \mathrm{~b}$ & $0,231 \mathrm{a}$ \\
\hline C.V. $(\%)$ & 28,02 & 20,63 & 25,67 & 25,0 \\
\hline
\end{tabular}

Médias seguidas de mesma letra na coluna são estatisticamente iguais, pelo teste de $\mathrm{F}(\mathrm{P}<0,05)$

Devido a questões relacionadas ao manejo da granja comercial, os leitões alojados nas celas construídas em alvenaria foram desmamados três dias mais tarde do que aqueles que se encontravam nas celas de ardósia. Dessa forma, os maiores PD e GPT foram observados nos leitões alojados nas celas de alvenaria, uma vez que a desmama desses animais ocorreu aos 21 dias, enquanto a desmama dos leitões alojados nas celas construídas em ardósia ocorreu aos 18 dias, conforme o cronograma de manejo da granja.

Mesmo com idades de desmame diferentes, os leitões apresentaram GPD semelhante, mostrando que o GP sofreu maior influência da idade à desmama e menor influência do material de construção.

Quando o PD dos leitões alojados nas celas confeccionadas em ardósia foi comparado ao manual de produção da linhagem comercial utilizada, pôde-se notar que os leitões que se encontravam neste tratamento apresentaram melhora de $1,9 \%$ no peso final, ao passo que os das celas em alvenaria de tijolos furados se desenvolveram de acordo com o manual da genética utilizada (Pen Ar Lan).

Diferentemente de PANDORFI et al. (2005), os resultados encontrados para desempenho podem ser atribuídos aos tratamentos avaliados, visto que os leitões que estavam alojados nas celas-maternidade confeccionadas em ardósia apresentarem maior frequência do comportamento mamando.

\section{CONCLUSÕES}

Os materiais de construção modificaram o ambiente témico no interior das instalações, afetando o comportamento de matrizes e leitões; entretanto, o desempenho dos leitões não foi afetado negativamente pelas celas confeccinadas em ardósia. Portanto, a ardósia pode ser uma alternativa à alvenaria, na construção de celas-maternidade de suínos, visto que esse é um material de construção que, geralmente, apresenta menor custo que a alvenaria de tijolos furados, notamente em algumas partes do Brasil, como o que ocorre na região onde foi conduzido o trabalho. 


\section{REFERÊNCIAS}

ALBUQUERQUE, F.C.; PONTEZ, M.R.; ALVEZ, J.N. Efeito residual de formulações de lambdacyhalothrin no tratamento de superfícies para o controle de Blattella germanica (dictyoptera: blattellidae). Arquivos do Instituto Biológico, São Paulo, v.70, n.4, p.467-471, out./dez. 2003.

\section{ASSOCIAÇÃO BRASILEIRA DOS MINERADORES E BENEFICIADORES DE MINAS} GERAIS. Mineração. Disponível em: <www.amarmg.com.br〉. Acesso em: 7 maio 2010.

BAÊTA, F.C.; SOUZA, C.F. Ambiência em edificações rurais - Conforto animal. Viçosa: Editora UFV, 1997. 245 p.

BORGES, G. Utilização da pressão sonora (ruído) como indicativo de bem-estar animal na produção industrial de suínos. 2008. 139 f. Dissertação (Mestrado em Física do Ambiente Agrícola) - Escola Superior de Agricultura "Luiz de Queiroz", Universidade de São Paulo, Piracicaba, 2008.

BRANCO, P.M. As rochas. Disponível em: <www.cprm.gov.br/publique/cgi/cgilua.exe/ sys/start.htm?infoid=1107\&sid=129\#metamorfica $>$. Acesso em: 8 fev. 2010.

BUFFINGTON, D.E.; COLLAZO AROCHO, A.; CANTON, G.H.; PITT, D. Black globe humidity index (BGHI) as a comfort equation for dairy cows. Transactions of the ASAE, St. Joseph, v.24, n.3, p.711-714, 1981.

CAMPOS, A.T.; KLOSOWSKI, E.; SANTOS, W.B.R.; GASPARINA, E.; CAMPOS, A.T.

Caracterização do microambiente em secção transversal de um galpão tipo "free-stall" orientado na direção norte-sul. Engenharia Agrícola, Jaboticabal, v.24, n.1, p.1-8, 2004.

CHIODI FILHO, C.; RODRIGUES, E.P.; ARTUR, A.C. Ardósias de Minas Gerais, Brasil: características geológicas, petrográficas e químicas. Geociências, São Paulo, v.22, n.2, p.119-127, 2003.

CORDEIRO, M.B.; TINÔCO, I.F.F.; OLIVEIRA, P.A.V.; MENEGALI, I.; GUIMARÃES, M.C.C.; BAÊTA, F.C.; SILVA, J.N. Efeito de sistemas de criação no conforto térmico ambiente e no desempenho produtivo de suínos na primavera. Revista Brasileira de Zootecnia, Viçosa-MG, v.36, n.5, p.1.597-1.602, 2007.

COSTA, A.G.; CAMPELLO, M.S.; PIMENTA, V.B. Rochas ornamentais e de revestimento de Minas Gerais: Principais ocorrências, caracterização e aplicações na indústria da construção civil. Geonomos, Belo Horizonte, v.7, n.1, p.9-13, 2001.

ESMAY, M.L. Principles of animal environment. West Port CT: ABI, 1982. 325 p.

FERREIRA, R.A.; CHIQUIERI, J.; MENDONÇA, P.P.; MELO, T.V.; CORDEIRO, M.D.

SOARES, R.T.R.R.N. Comportamento e parâmetros fisiológicos de leitões nas primeiras 24 horas de vida. Ciência e Agrotecnologia, Lavras, v.31, n.6, p.1.845-1.849, 2007.

MARTINS, T.D.D.; COSTA, A.N. Desempenho e comportamento de fêmeas suínas lactentes criadas em climas tropicais. Archivos de Zootecnia, Córdoba, v.57, n.1, p.77-88, 2008.

MARTINS, T.D.D.; COSTA, A.N.; SILVA, J.H.V. Respostas termorreguladoras de matrizes suínas híbridas em lactação, mantidas em ambiente quente. Ciência e Agrotecnologia, Lavras, v.32, n.3, p.961-968, 2008a.

MARTINS, T.D.D.; COSTA, A.N.; SILVA, J.H.V.; VALENÇA, M.R.B.; LUDKE, J.V. Postura e comportamento lactacional de matrizes suínas mantidas sob condições de temperatura ambiente elevada. Revista Biotemas, Santa Catariana, v.21, n.4, p.137-145, 2008 b.

NÄ̈̈S, I.A.; CAMPOS, L.S.L.; BARACHO, M.; TOLON,Y.B. Uso de redes neurais artificiais na identificação de vocalização de suínos. Engenharia Agrícola, Jaboticabal, v.28, n.2, p.204-216, 2008. 
NÄÄS, I.A. Princípios do conforto térmico na produção animal. São Paulo: Ícone, 1989. 183 p. OLIVEIRA, P.A.V.; SILVA, A.P. As edificações e detalhes construtivos voltados para o manejo de dejetos na suinocultura. Concórdia: Embrapa Suínos e Aves, 2006.

PANDORFI, H.; SILVA, I.J.O. ; CARVALHO, J.L.; PIEDADE, S.M.S. Estudo do comportamento bioclimático de matrizes suínas alojadas em baias individuais e coletivas, com ênfase no bem-estar animal na fase de gestação. Engenharia Rural, Piracicaba, v.17, n.1, p.1-10, 2006.

PANDORFI, H.; SILVA, I.J.O.; MOURA, D.J.; SEVEGNAN, K.B. Microclima de abrigos escamoteadores para leitões submetidos a diferentes sistemas de aquecimento no período de inverno. Revista Brasileira de Engenharia Agrícola e Ambiental, Campina Grande, v.9, n.1, p.99106, 2005.

PANDORFI, H.; SILVA, I.J.O.; MOURA, D.J.; SEVEGNAN, K.B.N. Análise de imagem aplicada ao estudo do comportamento de leitões em abrigo escamoteador. Engenharia Agrícola, Jaboticabal, v.24, n.2, p.274-284, 2004.

SAMPAIO, C.A.P.; NÄÄS, I.A.; SALGADO, D.D.; QUEIRÓS, M.P.G. Avaliação do nível de ruído em instalações para suínos. Revista Brasileira de Engenharia Agrícola e Ambiental, Campina Grande, v.11, n.4, p.436-440, 2007.

SILVA, I.J.O.; PANDORFI, H.; PIEDADE, S.M.S. Uso da zootecnia de precisão na avaliação do comportamento de leitões lactentes submetidos a diferentes sistemas de aquecimento. Revista Brasileira de Zootecnia, Viçosa-MG, v.34, n.1, p.220-229, 2005.

SILVA, I.J.O. Qualidade do ambiente e instalações na produção industrial de suínos. In: SIMPÓSIO INTERNACIONAL DE SUINOCULTURA, 1999, São Paulo. Anais. São Paulo: Gessuli, 1999. p.108-121.

SILVA, K.O.; NÄÄS, I.A.; TOLON, Y.B.; CAMPOS, L.S.L.; SALGADO, D.D. Medidas do ambiente acústico em creche de suínos. Revista Brasileira de Engenharia Agrícola e Ambiental, Campina Grande, v.11, n.3, p.339-344, 2007.

SOUZA, G. P. P. A influência do ambiente físico e social no bem-estar de leitões desmamados. 2007. 85 f. Dissertação (Mestrado em Agroecossistemas). Faculdade de Ciências Agrárias, Universidade Federal de Santa Catarina, Florianópolis, 2007.

TEIXEIRA, V.H. Construções e ambiência. Lavras: FAEPE, 1997. 181 p.

TURCO, S.H.N.; FERREIRA, A.S.; OLIVEIRA, R.F.M.; AGUIAR, M.A.; CECON, P.R.; ARAÚJO, G.G.L. Desempenho de porcas e leitões em maternidade com diferentes sistemas de acondicionamento térmico no inverno. Revista Brasileira de Zootecnia, Viçosa-MG, v.27, n.5, p.988-993, 1998. 